Supplement of The Cryosphere Discuss., 9, 1345-1381, 2015

http://www.the-cryosphere-discuss.net/9/1345/2015/

doi:10.5194/tcd-9-1345-2015-supplement

(c) Author(s) 2015. CC Attribution 3.0 License.

(c) (i)

Supplement of

\title{
Albedo reduction caused by black carbon and dust accumulation: a quan- titive model applied to the western margin of the Greenland ice sheet
}

\author{
T. Goelles and C. E. Bøggild
}

Correspondence to: T. Goelles (thomas.golles@unis.no, thomas.goelles@gmail.com) 
Figure S1 shows the simulated surface height evolution of KAN_M and S5 facilitating MAR models precipitation.

Compared to data from Van As et. al.,2012 station KAN_M agrees well from 2009 to 2011 but the surface ablation of station S5 is underestimated. This might be due to high winds at that location not represented in the model. Hence, the snow layer in the model is too thick.

Figure S2 displays a comparison of data and modelled albedo of station S5 from 2009 until 2013. All the years use the same parameters set optimised for 2011.

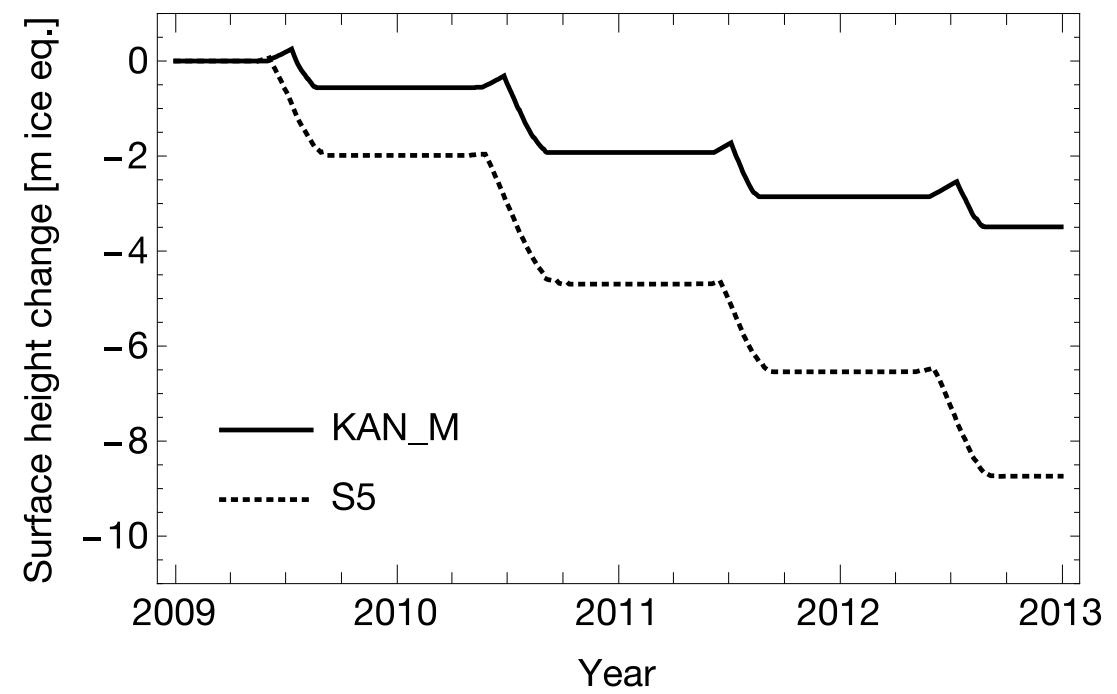

FiguRE S1. Surface height change of stations S5 and KAN_M.

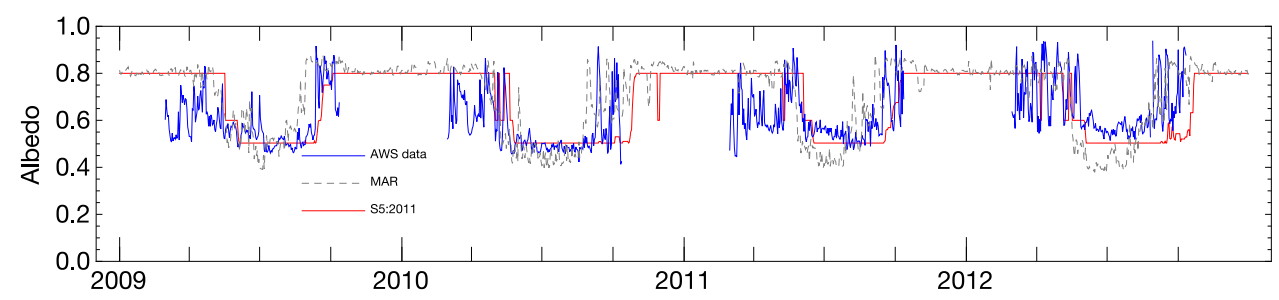

FiguRE S2. Albedo data and simulation for station S5 with parameters optimised for 2011.

Van As, D., Hubbard, A. L., Hasholt, B., Mikkelsen, A. B., van den Broeke, M. R. and Fausto, R. S.: Large surface meltwater discharge from the Kangerlussuaq sector of the Greenland ice sheet during the record-warm year 2010 explained by detailed energy balance observations, The Cryosphere, 6(1), 199-209, doi:10.5194/tc-6-199-2012, 2012. 